\title{
Ciências forenses: princípios éticos e vieses
}

Franciéllen de Barros ${ }^{1}$, Barbara Kuhnen ${ }^{1}$, Mônica da Costa Serra ${ }^{1}$, Clemente Maia da Silva Fernandes ${ }^{1}$

1. Universidade Estadual Paulista "Júlio de Mesquita Filho", Araraquara/SP, Brasil.

\section{Resumo}

As ciências forenses empregam conhecimentos científicos e técnicas diversas para apurar crimes e outros assuntos legais - cíveis, penais ou administrativos. Sua principal função é viabilizar as investigações relativas à justiça civil e criminal, visando esclarecer as questões do sistema de segurança pública. Porém, com o avanço tecnológico, certos crimes - e, consequentemente, a prática forense tornaram-se mais complexos. Como todas as profissões, as ciências forenses são regidas por princípios e práticas éticas que acrescentam deveres e responsabilidades ao profissional, objetivando agregar qualidade tanto no plano técnico quanto humano e evitar vieses. Com isso, este artigo apresenta reflexões sobre questões éticas e vieses relacionados à atuação dos profissionais das ciências forenses.

Palavras-chave: Ciências forenses. Ética. Bioética.

\section{Resumen}

Ciencias forenses: principios éticos y sesgos

Las ciencias forenses utilizan conocimientos científicos y técnicas para investigar delitos y otros asuntos legales (civiles, penales o administrativos). Su función principal es posibilitar las investigaciones relativas a la justicia civil y penal, con el objetivo de resolver problemas del sistema de seguridad pública. Sin embargo, con el avance tecnológico, ciertos delitos -y, en consecuencia, la práctica forense- se han vuelto más complejos. Al igual que todas las profesiones, las ciencias forenses se rigen por principios y prácticas éticas que agregan deberes y responsabilidades al profesional, con el objetivo de mejorar la calidad técnica y humana y evitar sesgos. Este artículo presenta reflexiones sobre las cuestiones éticas y los sesgos relacionados con la actuación de los profesionales de las ciencias forenses.

Palabras clave: Ciencias forenses. Ética. Bioética.

\section{Abstract}

\section{Forensic sciences: ethical principles and biases}

Forensic sciences use diverse scientific and technical knowledge to investigate crimes and other legal matters - civil, criminal, or administrative. Its primary role is to enable investigations related to civil and criminal justice, aiming to clarify issues of the public security system. But with technological advances, certain crimes, and consequently forensic practice, have become more complex. Like all professions, forensic sciences are governed by ethical principles and practices that include duties and responsibilities, aiming to add both technical and human quality and avoid biases. Thus, this article presents reflections on ethical issues and biases related to the forensic science professionals' work.

Keywords: Forensic sciences. Ethics. Bioethics. 
As ciências forenses são compostas por todos os conhecimentos científicos e técnicas utilizados para apurar crimes e assuntos legais diversos (cíveis, penais ou administrativos) ${ }^{1}$. Esse campo tem a função de estudar e interpretar os vestígios que caracterizam as infrações para esclarecer os atos delituosos e colaborar com as autoridades responsáveis pela aplicação da lei ${ }^{2}$. Nas investigações criminais, a principal tarefa do perito forense é confirmar a autoria do delito ou excluir o envolvimento do(s) suspeito(s) - evitando a condenação injusta de inocentes - por meio de métodos que permitem determinar com relativa precisão, por exemplo, se uma pessoa estava na cena do crime $^{3,4}$.

Segundo Silva e Rosa ${ }^{5}$, o principal papel desta ciência é auxiliar as investigações relativas às justiças civil e criminal, empregando métodos científicos para averiguar danos, mortes e crimes inexplicados. A partir do estudo das evidências colhidas no âmbito da investigação, as ciências forenses ajudam a identificar suspeitos e a elucidar determinado crime, criando hipóteses sobre o ocorrido. Têm, portanto, o objetivo principal de pesquisar nos vestígios do fato criminoso os elementos necessários para formalizar o exame de corpo de delito, produzindo a prova para instruir o processo penal ${ }^{6}$.

Nos primórdios da estruturação do campo, as práticas forenses eram desempenhadas por profissionais de formação genérica 7 . Porém, com a evolução tecnológica, certos crimes tornaram-se mais complexos, tornando necessária a participação de profissionais especializados em outras áreas da ciência, com o intuito de realizar investigações policiais mais eficazes ${ }^{6}$. Dessa forma, muitas áreas como antropologia, criminologia, entomologia, odontologia, toxicologia, engenharia, patologia, psicologia e medicina, entre outras - passaram a compor e auxiliar as ciências forenses, consideradas campo interdisciplinar ${ }^{3}$. Sua área de atuação é, portanto, bastante abrangente, buscando servir à Justiça e à sociedade.

A interdisciplinaridade do campo engendra diversas metodologias para a execução dos exames periciais ${ }^{3,6}$. Assim como o juiz lança mão de vários elementos para aplicar a lei, os peritos utilizam os conhecimentos das diversas áreas da ciência para analisar os vestígios encontrados na cena de um crime ${ }^{6,7}$.

Diferentemente de outras disciplinas científicas, o Direito é ferramenta usual no campo forense ${ }^{8}$.
Apesar disso, a ciência e o Direito obtêm informações e resultados de maneiras diferentes ${ }^{8,9}$. Durante a investigação, uma hipótese é proposta e experimentos são realizados para testá-la; se os dados encontrados não a contrapõem, ela ganha suporte, fundamentando-se e sendo aceita como razoável e confiável. Porém, o perito trabalha com certas limitações da própria ciência, pois mesmo com os avanços tecnológicos nem sempre as conclusões são precisas, o que pode levar as descobertas a serem questionadas. O Direito opera de forma contraditória, atuando às vezes sem exigir quaisquer dados de apoio para fundamentar dúvidas trazidas por advogado de defesa. Em outros momentos, há casos em que a acusação pode não validar a admissibilidade do método proposto pela defesa. Contudo, os métodos das ciências forenses têm sido validados e testados continuamente na arena científica ${ }^{10}$.

Assim como todas as atividades profissionais, as ciências forenses são regidas por princípios e práticas éticas que visam delinear os deveres e as responsabilidades de cada trabalhador para agregar qualidade não somente à área técnica, mas também humana do ofício. Os peritos que não seguem princípios éticos violam as normas deontológicas, independentemente do campo em que atuam.

Com isso, este trabalho objetiva analisar aspectos éticos e deontológicos da atuação profissional em ciências forenses. Para fundamentar esta reflexão foi realizado levantamento em três bases de dados PubMed, Web of Science e Embase -, utilizando os descritores "ciências forenses", "ética", "vieses", "deontologia", "princípios éticos", "bioética", "ética profissional" e "perito". Foram selecionados artigos em inglês ou português que discutissem dilemas éticos e vieses nas ciências forenses, assim como capítulos de livros que abordassem o tema.

\section{Ética e ciências forenses}

Segundo Dinkar, Frabkena descreveu a ética como filosofia da moralidade ou pensamento filosófico sobre moral, problemas morais e julgamento moral. Contudo, ética, em sentido restrito, é diferente de moral. A ética se baseia em conhecimento e pensamento; moralidade se baseia em crença e sentimento ${ }^{11}$. 
A ética estipula o comportamento correto do indivíduo, permitindo ao ser humano discernir o certo do errado, e a transgressão de regras ou normas vigentes na sociedade resulta em atitudes pouco éticas $^{2,12}$. O comportamento de cada pessoa é modulado desde o nascimento pelos pais, mas influências externas presentes no cotidiano interferem nesse comportamento e na própria personalidade ${ }^{2}$.

Durante a vida, as pessoas são limitadas tanto por regras particulares quanto profissionais, sendo a prática trabalhista regida por normas deontológicas $^{2,13}$. O profissional que emite resultado falso trai a confiança pública, prejudica outros profissionais e coloca a justiça em risco. Uma das maneiras mais eficazes de se proteger de violações éticas é estar atento aos caminhos que levam ao erro ${ }^{14}$.

O perito deve ser imparcial ao transmitir informações à Justiça, pois a sociedade, as vítimas e os suspeitos têm direitos relacionados aos deveres deste profissional. Para a sociedade, o principal dever do perito se baseia na confiança nele depositada. Para a acusação, a vítima e o suspeito, esse profissional é responsável pelo resultado correto da investigação, que deve ser conduzida de maneira eficiente e eficaz. Muitas vezes, a acusação pode depender completamente do relatório apurado pelo perito ${ }^{2,13,15}$.

Portanto, o sistema judicial deve poder contar inteiramente com o trabalho dos especialistas, pois são encarregados de estabelecer parâmetros úteis para identificar a autoria do crime ou isentar o suspeito da responsabilidade penal ${ }^{2,13,15}$. Neste sentido, além da obediência à legislação pertinente, entende-se que a atuação dos peritos deve se pautar na observância de normas deontológicas e princípios éticos.

\section{Prática ética e o perito}

Nas ciências forenses existem muitas áreas que atuam separadamente, mas que se unem no final para fornecer resultados precisos e, assim, confirmar a autoria do crime ou descartar o envolvimento do(s) suspeito(s). Para que seu trabalho tenha autoridade, o perito deve ter experiência em sua área, mas para se tornar especialista é necessário que tenha conhecimento amplo e aprofundado, sendo desta forma competente para formular seu relatório final ${ }^{2,12,15}$.
Magistrados confiam em peritos. Os tribunais costumam aceitar sem contestação laudos periciais, sobretudo devido à dificuldade que leigos em temas técnicos têm para questionar as informações fornecidas. Assim, é primordial que as evidências apresentadas pelos peritos sejam confiáveis, precisas e o mais livre de vieses possível ${ }^{16}$.

A complexidade da análise e interpretação de dados forenses é tema bastante debatido ${ }^{17}$. Preocupações sobre a admissibilidade de evidências e depoimentos de especialistas foram amplamente expressas em relação às taxas de validação e erro em métodos usados nas investigações ${ }^{18}$. Segundo Hiss, Freund e Kahana ${ }^{18}$, quando um perito é chamado a fornecer opinião especializada sobre assunto fora do escopo de sua área profissional, espera-se que seja honesto o suficiente para recusar seus serviços. Os autores revisaram a competência de peritos-testemunhas em diversos casos forenses e encontraram incongruências e discrepâncias nos resultados das análises clínicas e forenses nas áreas analisadas ${ }^{18}$.

Para Dinkar ${ }^{2}$, o problema ético mais significante no campo forense, identificado em pesquisa feita com advogados e peritos associados à Academia Americana de Ciências Forenses, é a competência. Neste contexto, o autor sugere dois requisitos éticos: emprego de métodos confiáveis e relatório restrito à área de atuação do perito, redigido com honestidade quanto à sua qualificação ou experiência.

O perito deve apresentar comportamento eticamente correto ao testemunhar sobre assunto específico, não podendo avultar suas qualificações ou experiência ${ }^{2}$. Não é ético - tampouco legal dar falsas declarações sobre sua carreira ${ }^{12,15}$, e assumir a responsabilidade de analisar uma investigação sem possuir experiência para isso contraria os valores éticos das ciências forenses. Não sendo qualificado para determinado assunto, o perito não deve apresentar sua opinião científica ${ }^{2,12}$.

Este tipo de profissional cotidianamente se depara com criminalidade, violência e morte. Devido à urgência e complexidade das atividades desenvolvidas nesta seara, Walterscheid ${ }^{14}$ acredita que questões políticas, o elevado nível de estresse e vieses pessoais podem dar margem para imprudência. Com isso, o autor entende que o cientista forense deve possuir habilidades e conhecimento técnico, educação e treinamento adequados. 
Nesses casos, a ética apresenta padrões de conduta sustentados por justiça e coerência.

Na mesma linha, Murdock e Holmes ${ }^{19}$ entendem que os profissionais que atuam em ciências forenses devem ser objetivos, demostrando como chegam às conclusões apresentadas em seus laudos. Neste sentido, treinamento e adesão ao código de ética profissional são importantes. O profissional ético obtém resultados de forma clara e explícita, sem qualquer viés, não se estendendo além de suas habilidades, competências ou conhecimentos, reconhecendo a importância de realizar investigação minuciosa antes de chegar a uma conclusão. Yadav ${ }^{20}$, por sua vez, lembra que resultados periciais, bem como a opinião de peritos, jamais devem ser falsificados, recortados, adaptados ou de forma alguma modificados para atender a terceiros, seja por questão política, militar, racial, financeira ou outras.

\section{Viés, parcialidade e o perito}

Em ciências forenses, "viés" significa descoberta - direta ou indiretamente parcial, intencional ou não - que pode beneficiar um lado e prejudicar outro ${ }^{2,10}$. Está relacionado a posicionar-se a favor ou contra uma pessoa ou coisa, podendo assumir muitas formas, e está associado a opinião adversa baseada não em evidências objetivas, mas em sentimentos hostis motivados por hábitos de julgamento ou generalizações precipitadas.

A subordinação do perito às autoridades responsáveis pela aplicação da lei pode gerar viés ${ }^{2,21}$. Starrs ${ }^{22}$ cita o caso de investigador que, ao entregar para o especialista em balística forense pistola usada em tiroteio, informou-o que sabia que aquela arma havia sido utilizada pelo suspeito, solicitando ao perito que confirmasse esta hipótese.

A análise da cena ou da evidência pode também sofrer viés se o perito se envolver emocionalmente com o caso, o que pode levá-lo a ignorar detalhes que desafiem sua crença ${ }^{23}$. Similarmente, a indiferença e a falta de empenho podem causar viés quando o perito aceita a opinião alheia sem chegar às próprias conclusões, ocasionando perda de objetividade ${ }^{24}$.

$O$ viés também pode interferir nas opiniões de pessoas que convivem com indivíduos que compartilham suas crenças e perspectivas. A convivência com sujeitos com convicções divergentes demanda a defesa das próprias opiniões, o que leva o ser humano a tender a se agrupar com aqueles que compartilham sua visão de mundo. Argumenta-se ser preferível ter suas opiniões desafiadas, pois isso exige processar informações em vez de simplesmente aceitá-las. Isto é importante para superar o viés, pois faz com que sejam examinadas todas as possibilidades, permitindo formar opinião imparcial ${ }^{24}$.

Os peritos, por meio dos resultados e conclusões apresentados em seus relatórios, auxiliam profissionais de diversas áreas e desempenham papel crítico nos processos judiciais e na administração da justiça. Tais provas cooperam para a condenação de culpados e podem evitar a injusta condenação de inocentes ${ }^{25}$. Dror ${ }^{25}$ lembra que é o perito quem observa e interpreta os dados e, portanto, as evidências forenses são mediadas por fatores humanos e de percepção, atenção e associação. O autor afirma que os especialistas podem ser expostos a informações irrelevantes para a execução do seu trabalho - como confissões, ficha criminal ou identificação de um suspeito, entre outros $^{25}$. Tais dados podem ocasionar ou somar vieses. Relatórios periciais devem ser imparciais, apropriadamente circunscritos pelo que as evidências realmente apoiam ${ }^{25}$. Conclusões incorretas ou exageradas podem ser originadas por informações errôneas, que causam parcialidades ${ }^{26}$.

O modo como percepções e julgamentos humanos podem ser influenciados por outros fatores irrelevantes para certo caso é denominado "viés cognitivo". Este inclui: 1) viés contextual, quando informações irrelevantes dadas por terceiros influenciam as conclusões; 2) viés de confirmação, quando crenças ou suposições pré-existentes atuam na interpretação de informações e evidências; e 3) prevenção de dissonância cognitiva, quando o profissional não aceita novas informações que não correspondem à sua conclusão preliminar ${ }^{27}$. Vieses cognitivos são subjetivos e prejudicam a confiabilidade das evidências, fazendo com que o profissional veja e registre algo que não existia ou deixe de ver e registrar algo que existiu.

As conclusões dos profissionais influenciados por vieses não devem ser confundidas com o desejo proposital de testemunhar falsamente; frequentemente esses peritos não têm consciência de que suas conclusões não são corretas ou confiáveis $^{28}$. Fatores cognitivos são relevantes para tomar 
decisões e podem influenciar a compreensão, análise e interpretação dos dados em casos periciais ${ }^{29}$.

Vários autores propuseram soluções para esses vieses e escreveram sobre seu impacto nas ciências forenses, buscando limitar os fatores que influenciam os profissionais que atuam nesta seara para possibilitar observações e conclusões imparciais e objetivas ${ }^{30}$. Restringir o acesso a informações não relacionadas à tarefa e controlar a ordem e o momento de fornecer dados têm sido métodos propostos para reduzir a chance de parcialidade ${ }^{31}$. No entanto, estudo envolvendo 403 peritos observou que a maioria dos participantes rejeitava a necessidade de procedimentos para minimizar vieses cognitivos, mostrando-se ainda incapazes de reconhecer a predisposição para vieses ${ }^{26}$.

\section{Viés de confirmação e institucional}

O viés de confirmação corresponde à perda da capacidade de ser objetivo e ocorre quando o indivíduo procura confirmar suas crenças e hipóteses ${ }^{32}$ buscando indícios que the permitam interpretar os dados de modo a favorecê-las ${ }^{33}$. Desta forma, evidências positivas são privilegiadas em detrimento de informações negativas ${ }^{24}$. Em determinados casos, o indivíduo está tão comprometido com suas ideias que desconsidera hipóteses e explicações de outros ${ }^{33}$.

A disputa para beneficiar ou promover interesses no tribunal, independentemente do motivo e afetando negativamente ou minimizando os interesses da outra parte, é definida como viés institucional $^{2}$. Segundo Dinkar ${ }^{2}$, em 1994 pesquisa identificou 85 casos, realizados a partir de 1974, nos quais consciente ou inconscientemente promotores utilizaram evidências contaminadas, levando à condenação de inocentes ou absolvição de culpados. Foram libertados ainda 48 suspeitos depois que se constatou que as acusações contra eles se basearam em provas fabricadas, ou porque a evidência exoneradora ou exculpadora foi retida ${ }^{2}$.

Se as conclusões do perito se basearem em indícios fundamentados e objetivos, é considerado tendencioso privilegiar informações que se encaixam em suas crenças pessoais ${ }^{32}$. Se o perito ignorar a evidência que contradiz as próprias conclusões, a objetividade é perdida ${ }^{24}$. É comum o ser humano argumentar de forma positiva sobre suas crenças e hipóteses, mesmo se elas forem confrontadas com evidências contraditórias. As pessoas apoiam suas reivindicações mais facilmente do que as contradizem, pois tendem a resistir à possibilidade de estar erradas. Portanto, conclusões podem ser desafiadas e até mesmo mudadas se a objetividade for contaminada por vieses ${ }^{23}$.

Três erros comuns são encontrados nas ciências forenses para compreender o viés de confirmação: violação ética, erros honestos e supervisão tendenciosa. A violação ética pode abranger impressões fabricadas, resultados estimados sem exames completos, resultados intencionalmente errados ou acobertamento de erros. Já os erros honestos podem envolver ausência de capacitação, pressão para realizar tarefas, excesso de trabalho e erros administrativos ou tendência a concordar com o trabalho de outra pessoa ${ }^{24}$.

Dror e Cole ${ }^{34}$ apontaram três preocupações com a influência das conclusões de peritos com base tendenciosa: vieses cognitivos afetam todos os profissionais, em qualquer área de atuação das ciências forenses; as conclusões baseadas em vieses são ainda mais influentes porque os próprios especialistas acreditam nelas; e tem havido resistência em reconhecer tais vieses e aceitar medidas adequadas para combatê-los.

\section{Tipos de parcialidade}

Segundo Nickerson ${ }^{33}$, o viés de confirmação pode tomar diversas formas. Para Byrd ${ }^{24}$, é importante entender como o viés penetra no processo cognitivo, além de entender os níveis em que ele é possível:

- define-se "efeito da expectativa" quando se espera determinado resultado de uma observação inicial ou análise, porque a antecipação conduz ao resultado desejado;

- dar atenção apenas aos itens de interesse e desconsiderar informações que contradizem aquilo que se espera é definido como "atenção seletiva". O ser humano tem a capacidade de focar sua atenção e ignorar ou mesmo não perceber o que está ao redor. Aliar a "atenção seletiva" ao "efeito da expectativa" estimula a mente a apenas encontrar informações que confirmem aquilo em que o indivíduo acredita, desconsiderando todos os outros dados que não Ihe são interessantes; 
- define-se "efeito da função" quando duas pessoas, devido ao seu ofício, coletam informações díspares em uma cena de crime, pois cada especialista focará diferentes aspectos segundo a função que exerce;

- o ato de aceitar opiniões, crenças e comportamento de colegas é definido como "efeito de conformidade", pois o especialista se sujeita às opiniões dos colegas;

- define-se "percepção determinada pela necessidade" quando forte motivação faz com que o resultado almejado seja obtido. Essa motivação pode surgir do desejo de ajudar a resolver crimes;

- a tendência a acreditar que afirmação ou conclusão é verdadeira apesar da falta de evidências convincentes é definida como "intervalo de positividade", predispondo as pessoas a afirmar aquilo que creem ser verdade;

- chama-se "efeito de primazia" quando, em longo processo de coleta de informações, os primeiros dados reunidos são privilegiados para orientar a conclusão e as consequentes decisões. Opiniões formadas precocemente tendem a influenciar informações posteriores, permitindo que qualquer dado transmitido no início da investigação gere o resultado ou a conclusão do caso;

- "confiança excessiva" pode igualmente causar viés, pois, mesmo diante de evidências contraditórias, pessoas que se julgam sempre certas tendem a defender suas crenças.

Tais vieses caracterizam diferentes tipos de parcialidades, podendo levar a conclusões e laudos periciais tendenciosos. Nas ciências forenses, itens de evidência apresentados de forma sugestiva pelo investigador ou por outros analistas podem incitar o perito a determinado resultado ${ }^{35}$. Para Byrd ${ }^{24}$, tais comentários sugestivos podem corromper exames e análises e prejudicar as conclusões, mas as decisões são influenciadas por determinada quantidade de informações apenas até certo ponto.

Além de colocar em dúvida todas as descobertas, qualquer achado errôneo ou tendencioso deve ser revelado, pois diz respeito à responsabilidade profissional. Para Nickerson ${ }^{33}$, o viés de confirmação não é a única causa de erros, mas é significativo para a avaliação e análise de provas da cena do crime.
Como constatado, a atividade pericial está sujeita a vieses, que podem ocasionar parcialidade (mesmo que involuntária e/ou inconsciente) nos laudos. Conclui-se que, além do conhecimento técnico específico necessário à prática profissional, peritos precisam de treinamento e formação ética e legal para cumprir bem suas funções e prevenir vieses e parcialidades.

\section{O perito e a análise pericial}

O julgamento do perito embasa a prova científica no tribunal. Como está em contato direto com os investigadores, o especialista forense torna-se parte da equipe de aplicação da lei, cujo principal objetivo é "resolver o caso" contra o culpado. Nestas situações, muitas vezes as análises podem tender para a teoria policial sobre a ocorrência ao considerar determinações subjetivas ${ }^{2,15,21}$.

Valores éticos também são corroídos nesse processo graças às "armas contratadas" como peritos, ou seja, especialistas que têm afinidade com determinado advogado e tentam beneficiá-lo. O número de peritos eticamente corretos ultrapassa o de "armas contratadas", mas é difícil para o Judiciário distinguir especialistas tendenciosos dos honestos ${ }^{12}$.

Ainda que o perito faça parte da equipe que aplica a lei e auxilie a investigação com base nos dados que a polícia fornece para análise científica, ele não pode beneficiar a corporação ou o acusado, devendo atuar de forma independente e imparcial. Apesar disso, Dinkar ${ }^{2}$ questiona se de fato não há interferência policial nas opiniões transmitidas pelos peritos, pois muitos laboratórios científicos forenses estão vinculados aos Departamentos de Polícia.

Como responsável pelo combate ao crime, a polícia coleta os materiais necessários e os entrega aos peritos para análise, controlando o processo desde essa fase até a conclusão do exame pericial. Informações incomuns dadas sobre o caso podem também impelir o examinador a alcançar resultados conciliados a outras evidências ${ }^{2,15}$. Desta forma, a busca pela qualidade é fundamental e deve servir de alicerce das ciências forenses em seus esforços contínuos para melhorar produtos, serviços ou processos ${ }^{10,12}$.

Para que a evidência forense tenha qualidade, é necessário: 1) técnica autenticada; 2) titulação 
dos instrumentos utilizados na análise; 3) pessoas aptas a interpretar os dados; 4) diretrizes para evitar contaminação; 5) laboratório confiável; 6) equipe forense e laboratório capacitados para efetuar testes e contínua avaliação da sua capacidade de análise; e 7) aptidão do pessoal de suporte técnico e bom desempenho do laboratório. Os peritos devem ser competentes para alcançar a excelência no serviço forense, além de trabalhar com sistema de qualidade e abordagem correta $^{2,36}$. A maioria dos laboratórios prioriza protocolos validados e bem estabelecidos ${ }^{20}$.

As evidências da cena do crime devem ser preservadas, respeitando-se a cadeia de custódia. Muitas vezes a análise de casos se acumula pela falta de laboratórios criminais, recursos adequados e pessoal qualificado, suscitando preocupações sobre a eficiência e a eficácia do sistema de justiça criminal. Nos Estados Unidos, por exemplo, alguns laboratórios podem eventualmente restringir o recebimento de materiais para análise para reduzir atrasos ${ }^{37}$. Segundo o Comitê para a Identificação das Necessidades da Comunidade Forense do Conselho Nacional de Pesquisa americano ${ }^{37}$, se as evidências ou os testes laboratoriais forem analisados de forma inadequada ou se houver subjetividade, incompetência ou ausência dos controles internos necessários, a decisão judicial resultante pode ser injusta ou equivocada.

A responsabilidade social da atividade pericial jamais deve ser esquecida pelos profissionais da área. Frequentemente seus relatórios, que embasam decisões judiciais, podem definir o destino de uma pessoa (com sua condenação ou absolvição). Além disso, identificar corpos, restos cadavéricos ou ossadas de modo equivocado pode ter, entre outras, repercussões jurídicas, patrimoniais e emocionais.

\section{Conduta profissional e ética}

O perito deve atender os mais altos padrões éticos e profissionais. Várias entidades do campo forense estabelecem códigos de conduta que devem ser regularmente avaliados e atualizados $^{10,13}$. Códigos de ética profissional estruturam princípios para auxiliar os especialistas a discernir o que é aceitável e orientar suas decisões e resolução de problemas, tendo como como base os valores profissionais da categoria ${ }^{38,39}$. Suas normas e diretrizes objetivam prevenir comportamentos considerados antiéticos ${ }^{40}$ e assegurar o profissionalismo ${ }^{41}$.

Nas ciências forenses atuam profissionais com diversas formações, como médicos, biomédicos, cirurgiões-dentistas, psicólogos, engenheiros, geólogos, biólogos, químicos, farmacêuticos, antropólogos, arqueólogos etc. Normalmente, os conseIhos profissionais de cada categoria estabelecem seu próprio código deontológico ${ }^{42}$, enfatizando os princípios que devem ser cumpridos em cada especialidade ${ }^{43}$. Tais conselhos têm a prerrogativa de aplicar sanções aos profissionais que infringirem essas normas.

Associações de peritos de diversos países também instituíram seus próprios códigos de conduta ${ }^{44}$, e laboratórios de criminalística públicos e privados devem adotar normas que contemplem os interesses da sociedade ${ }^{10,45}$. Não obstante, Gilman ${ }^{41}$ lembra que os códigos não excluem a autonomia moral do especialista e sua obrigação de raciocinar. Basicamente, peritos devem elaborar hipóteses e alternativas, resolver problemas, documentar suas atividades e abordar o trabalho laboratorial ${ }^{24}$ mantendo valores e padrões éticos que ajudam a estabelecer a qualidade, validade e autenticidade dos resultados ${ }^{20}$. Em seu estudo, Costa Filho e Abdalla-Filho ${ }^{46}$ observaram insatisfação dos peritos criminais entrevistados sobre as orientações éticas recebidas, concluindo ser preciso estabelecer referenciais éticos específicos para a prática pericial.

Os profissionais que atuam em ciências forenses devem ter formação científica adequada para efetivamente realizar processos analíticos no campo judicial. Estes especialistas precisam estar atentos a novos e potenciais avanços que possam melhorar sua prática atual, além de comportar-se de forma ética para superar os desafios do século $X X I^{10,12,15}$, evitando vieses e enfatizando interesses da sociedade.

\section{Considerações finais}

As ciências forenses abrangem profissionais de diversas áreas e com formações variadas, cujos conselhos profissionais muitas vezes adotam normas deontológicas elencadas nos 
respectivos códigos de ética. Porém, a atividade pericial apresenta características e necessidades específicas. Vieses são possíveis e podem resultar em relatórios tendenciosos, mesmo que a parcialidade seja inconsciente ou involuntária, e reconhecê-los é passo importante para implementar medidas de prevenção.

Peritos têm grande responsabilidade social. Suas atividades têm grande importância - e trazem grandes consequências - tanto para a Justiça como para a sociedade. Para desenvolver seu trabalho, o perito precisa de conhecimento técnico específico e sempre atualizado. Entende-se, portanto, que os profissionais das ciências forenses devem ter treinamento contínuo, assim como orientação e formação ética e legal voltadas para os dilemas e casos específicos de suas funções, buscando prevenir vieses e parcialidades.

Este trabalho foi realizado com apoio da Coordenação de Aperfeiçoamento de Pessoal de Nível Superior. Agradecemos à professora doutora Laura Bishop, do Kennedy Institute of Ethics, Georgetown University, Estados Unidos, pelo seu auxilio e pela receptividade durante a visita de Fernandes e Serra, e a Patricia Martin e Roxie France-Nuriddin pelo auxilio na Bioethics Research Library do mesmo instituto.

\section{Referências}

1. Garrido RG, Giovanelli A. Ciência forense: uma introdução à criminalística. Rio de Janeiro: Projeto Cultural; 2012.

2. Dinkar VR. Interpreting scientific expert evidence with special emphasis on the admissibility and probative value of DNA identification evidence [tese] [Internet]. Kottayam: Mahatma Gandhi University; 2005 [acesso 12 jan 2021]. Disponível: https://bit.ly/3pP6P8q

3. Chemello E. Ciência forense: impressões digitais. Quím Virtual [Internet]. 2006 [acesso 12 jan 2021]:1-11. Disponível: https://bit.ly/39NHare

4. Sebastiany AP, Pizzato MC, Del Pino JC, Salgado TDM. A utilização da ciência forense e da investigação criminal como estratégia didática na compreensão de conceitos científicos. Educ Quím [Internet]. 2013 [acesso 12 jan 2021];24(1):49-56. DOI: 10.1016/S0187-893X(13)73195-1

5. Silva PS, Rosa MF. Utilização da ciência forense do seriado CSI no ensino de química. Rev Bras Ensino Ciênc Tecnol [Internet]. 2013 [acesso 12 jan 2021];6(3):148-60. DOI: 10.3895/S1982-873X2013000300009

6. Calazans $\mathrm{CH}$, Calazans $\mathrm{SM}$. Ciência forense: das origens à ciência forense computacional [Internet]. In: Anais do XV Seminário Regional de Informática; 2005; Santo Ângelo. Santo Ângelo: Universidade Regional Integrada; 2005 [acesso 12 jan 2021]. Disponível: https://bit.ly/36HN5fo

7. Fachone P, Velho L. Ciência forense: interseção justiça, ciência e tecnologia. Rev Tecnol Soc [Internet]. 2007 [acesso 12 jan 2021];3(4):139-61. DOI: 10.3895/rts.v3n4.2498

8. Budowle B, Allard MW, Wilson MR, Chakraborty R. Forensics and mitochondrial DNA: applications, debates, and foundations. Annu Rev Genomics Hum Genet [Internet]. 2003 [acesso 12 jan 2021];4:119-41. DOI: 10.1146/annurev.genom.4.070802.110352

9. Bird SJ. Scientific certainty: research versus forensic perspectives. J Forensic Sci [Internet]. 2001 [acesso 12 jan 2021];46(4):978-81. DOI: 10.1520/JFS15081J

10. Budowle B, Bottrell MC, Bunch SG, Fram R, Harrison D, Meagher S et al. A perspective on errors, bias, and interpretation in the forensic sciences and direction for continuing advancement. J Forensic Sci [Internet]. 2009 [acesso 12 jan 2021];54(4):798-809. DOI: 10.1111/j.1556-4029.2009.01081.x

11. Dinkar VR. Op. cit. p. 402. Tradução livre.

12. Siegel JA. General forensic ethical dilemmas. In: Downs JCU, Swienton AR, editores. Ethics in forensic science [Internet]. Oxford: Academic Press; 2012 [acesso 4 fev 2021]. p. 59-79. DOI: 10.1016/ B978-0-12-385019-5.00003-8

13. Melson KE. Codes of ethics in forensic science societies: the organizational parameters of morality and conduct. In: Downs JCU, Swienton AR, editores. Ethics in forensic science [Internet]. Oxford: Academic Press; 2012 [acesso 12 jan 2021]. p. 81-135. DOI: 10.1016/B978-0-12-385019-5.00004-X 
14. Walterscheid JP. Robin T. Bowen: ethics and the practice of forensic science. Forensic Sci Med Pathol [Internet]. 2011 [acesso 12 jan 2021];7(3):306. DOI: 10.1007/s12024-010-9202-9

15. Willoughby FW 3rd, Thompson SE, Downs JCU. The forensic practitioner's quest for truth. In: Downs JCU, Swienton AR, editores. Ethics in forensic science [Internet]. Oxford: Academic Press; 2012 [acesso 4 fev 2021]. p. 27-57. DOI: 10.1016/B978-0-12-385019-5.00002-6

16. Camilleri A, Abarno D, Bird C, Coxon A, Mitchell N, Redman K et al. A risk-based approach to cognitive bias in forensic science. Sci Justice [Internet]. 2019 [acesso 12 jan 2021];59(5):533-43. DOI: 10.1016/ j.scijus.2019.04.003

17. Morgan RM, Bull PA. Forensic geoscience and crime detection: identification, interpretation and presentation in forensic geoscience. Minerva Medicoleg [Internet]. 2007 [acesso 12 jan 2021];127(2):73-89. Disponível: https://bit.ly/2O6fcyp

18. Hiss J, Freund M, Kahana T. The forensic expert witness: an issue of competency. Forensic Sci Int [Internet]. 2007 [acesso 12 jan 2021];68(2-3):89-94. DOI: 10.1016/j.forsciint.2006.06.004

19. Murdock JE, Holmes KJ. The conflicts between managerial responsibilities and the ethics of forensic science. J Forensic Sci Soc [Internet]. 1991 [acesso 12 jan 2021];31(2):151-61. DOI: 10.1016/S0015-7368(91)73130-7

20. Yadav PK. Ethical issues across different fields of forensic science. Egypt J Forensic Sci [Internet]. 2017 [acesso 12 jan 2021];7:10. DOI: 10.1186/s41935-017-0010-1

21. Hodge E. Guarding against error. AFTE J [Internet]. 1988 [acesso 4 fev 2021];20(3):290-3. Disponível: https://bit.ly/2YN23fu

22. Starrs JE. The forensic scientist and the open mind. J Forensic Sci Soc [Internet]. 1991 [acesso 12 jan 2021];31(2):111-49. DOI: 10.1016/S0015-7368(91)73129-0

23. Cline A. Confirmation bias: flaws in reasoning and arguments. Learn Religions [Internet]. Atheism and Agnosticism; 24 fev 2018 [acesso 12 jan 2021]. Disponível: https://bit.ly/3oNguel

24. Byrd JS. Confirmation bias, ethics, and mistakes in forensics. J Forensic Ident [Internet]. 2006 [acesso 5 fev 2021];56(4):511-25. Disponível: https://bit.ly/2LniwEe

25. Dror IE. Biases in forensic experts. Science [Internet]. 2018 [acesso 16 set 2020];360(6386):243. DOI: 10.1126/science.aat8443

26. Kukucka J, Kassin SM, Zapf PA, Dror IE. Cognitive bias and blindness: a global survey of forensic science examiners. J Appl Res Mem Cogn [Internet]. 2017 [acesso 12 jan 2021];6(4):452-9. DOI: 10.1016/ j.jarmac.2017.09.001

27. United States of America. Executive Office of the President. President's Council of Advisors on Science and Technology. Forensic science in criminal courts: ensuring scientific validity of feature-comparison methods [Internet]. Washington: Executive Office of the President; 2016 [acesso 12 jan 2021]. Disponível: https://bit.ly/3jhcotL

28. Bieber P. Measuring the impact of cognitive bias in fire investigation [Internet]. In: Proceedings of the $5^{\text {th }}$ International Symposium on Fire Investigation Science and Technology; 2012; College Park. Sarasota: National Association of Fire Investigators; 2012 [acesso 12 jan 2021]. Disponível: https://bit.ly/3robYoc

29. Acklin MW, Fuger K, Gowensmith W. Examiner agreement and judicial consensus in forensic mental health evaluations. J Forensic Psychol Pract [Internet]. 2015 [acesso 12 jan 2021];15(4):318-43. DOI: 10.1080/15228932.2015.1051447

30.Zapf PA, Dror IE. Understanding and mitigating bias in forensic evaluation: lessons from forensic science. Int J Forensic Ment Health [Internet]. 2017 [acesso 12 jan 2021];16(3):227-38. DOI: 10.1080/14999013.2017.1317302

31. Dror IE, Thompson WC, Meissner CA, Kornfield I, Krane D, Saks M, Risinger M. Letter to the editor: context management toolbox: a linear sequential unmasking (LSU) approach for minimizing cognitive bias in forensic decision making. J Forensic Sci [Internet]. 2015 [acesso 12 jan 2021];60(4):1111-2. DOI: 10.1111/1556-4029.12805 
32. Carroll RT. Confirmation bias. The Skeptics Dictionary [Internet]. 2016 [acesso 12 jan 2021]. Disponível: https://bit.ly/3oPde26

33. Nickerson RS. Confirmation bias: a ubiquitous phenomenon in many guises. Rev Gen Psychol [Internet]. 1998 [acesso 12 jan 2021];2(2):175-220. DOI: 10.1037/1089-2680.2.2.175

34. Dror IE, Cole SA. The vision in "blind" justice: expert perception, judgment, and visual cognition in forensic pattern recognition. Psychon Bull Rev [Internet]. 2010 [acesso 12 jan 2021];17(2):161-7. DOI: 10.3758/ PBR.17.2.161

35. Steele LJ. The defense challenge to fingerprints. Crim Law Bull [Internet]. 2004 [acesso $11 \mathrm{fev}$ 2019];40(3):213-40. Disponível: https://bit.ly/2O6IPzD

36. Fereday MJ, Koop I. European Network of Forensic Science Institutes (ENFSI) and its quality and competence assurance efforts. Sci Justice [Internet]. 2003 [acesso 12 jan 2021];43(2):99-103. DOI: 10.1016/ S1355-0306(03)71750-X

37. National Research Council. Committee on Identifying the Needs of the Forensic Sciences Community. Strengthening forensic science in the United States: a path forward [Internet]. Washington: National Academies Press; 2009 [acesso 12 jan 2021]. Disponível: https://bit.ly/3rn7le9

38. Frankel MS. Professional codes: why, how, and with what impact? J Bus Ethics [Internet]. 1989 [acesso 12 jan 2021];8(2-3):109-15. DOI: 10.1007/BF00382575

39. Professional code of ethics: definition and examples. Indeed [Internet]. 24 nov 2020 [acesso 12 jan 2021]. Disponível: https://indeedhi.re/3pSUujE

40. Schwartz MS. A code of ethics for corporate code of ethics. J Bus Ethics [Internet]. 2002 [acesso 12 jan 2021];41(1-2):27-43. DOI: 10.1023/A:1021393904930

41. Gilman SC. Ethics codes and codes of conduct as tools for promoting an ethical and professional public service: comparative successes and lessons [Internet]. Washington: [s.n.]; 2005 [acesso 12 jan 2021]. Disponível: https://bit.ly/3aCTtFE

42. Helton-Fauth W, Gaddis B, Scott G, Mumford M, Devenport L, Connelly S, Brown R. A new approach to assessing ethical conduct in scientific work. Account Res [Internet]. 2003 [acesso 12 jan 2021];10(4):205-28. DOI: 10.1080/714906104

43. Giorgini V, Mecca JT, Gibson C, Medeiros K, Mumford MD, Connelly S, Devenport LD. Researcher perceptions of ethical guidelines and codes of conduct. Account Res [Internet]. 2015 [acesso 12 jan 2021];22(3):123-38. DOI: 10.1080/08989621.2014.955607

44. Mario JR. A review of Anglo-American forensic professional codes of ethics with considerations for code design. Forensic Sci Inter [Internet]. 2002 [acesso 12 jan 2021];125(2-3):103-12. DOI: 10.1016/ S0379-0738(01)00645-4

45. Fisher BAJ. Ethics in the crime laboratory and in crime scene investigations. In: Downs JCU, Swienton AR, editores. Ethics in forensic science [Internet]. Oxford: Academic Press; 2012 [acesso 12 jan 2021]. p. 281-91. DOI: 10.1016/B978-0-12-385019-5.00010-5

46. Costa Filho PEG, Abdalla-Filho E. Diretrizes éticas na prática pericial criminal. Rev. bioét. (Impr.) [Internet]. 2010 [acesso 12 jan 2021];18(2):421-37. Disponível: https://bit.ly/36Flsni 
Franciéllen de Barros - Doutoranda - fran.dbrs@gmail.com

(ID) $0000-0001-5460-4334$

Barbara Kuhnen - Doutoranda - kuhnenbarbara@gmail.com

(iD) $0000-0003-2586-4772$

Mônica da Costa Serra - Livre-docente - monica.serra@unesp.br

(D) 0000-0001-8820-2982

Clemente Maia da Silva Fernandes - Doutor - c.face@terra.com.br

(D) 0000-0002-5401-6265

Correspondência

Mônica da Costa Serra - Universidade Estadual Paulista "Júlio de Mesquita Filho".

Faculdade de Odontologia de Araraquara. Rua Humaitá, 1.680 CEP 14801-903. Araraquara/SP, Brasil.

Recebido: $\quad 30.7 .2019$

Revisado: $\quad 30.9 .2020$

Aprovado: 23.12 .2020 